\title{
Performance Comparison of the Single Axis and Two-Axis Solar System using Adaptive Neuro- Fuzzy Inference System Controls
}

\author{
Chairul Imron ${ }^{1}$, Imam Abadi ${ }^{2, *}$, Ilham Amirul Akbar², Jauharotul Maknunah², \\ Yusilawati Ahmad Nor ${ }^{3}$, and Aep Saepul Uyun ${ }^{4}$ \\ ${ }^{1}$ Department of Mathematic, Sepuluh Nopember Institute of Technology, Jl. Teknik Kimia, \\ Surabaya 60111, East Java, Indonesia \\ ${ }^{2}$ Department of Engineering Physics, Sepuluh Nopember Institute of Technology, Jl. Teknik Kimia, \\ Surabaya 60111, East Java, Indonesia \\ ${ }^{3}$ Department of Biochemical-Biotechnology Engineering, Kuliyyah of Engineering \\ International Islamic University Malaysia (IIUM), Jl. Gombak, 53100, Selangor, Malaysia \\ ${ }^{4}$ Graduate School of Renewable Energy, Darma Persada University, Jl. Taman Malaka \\ Selatan No. 22, Pondok Kelapa, East Jakarta 13450, Indonesia
}

\begin{abstract}
Solar energy is one of the renewable energy that gets more attention from many countries. Solar photo voltaic (PV) takes the right position to get the maximum energy yield. The study was conducted by comparison of performance with two methods of tracking the sun with one axis and two axes by using ANFIS control (Adaptive Neuro-Fuzzy Inference System). The solar tracking system is a system that operates on the sun by using a light sensor and controls the photovoltaic to always perpendicular to the sun by changing the pitch and yaw axis of the sun tracing properties. LDR (Light Dependent Resistor) is one of the light sensors whose resistance changes depending on the intensity of incoming light. Direct current (DC )motor is used as a PV drive panel in a solar tracking system. A two-axis solar tracking system has a greater power output than a tracking system with a single photovoltaic panel that does not use a tracking system (fixed).
\end{abstract}

Keywords: Direct current motors, light sensors, performance index, photovoltaic, pitch, yaw

\section{Introduction}

Solar energy is one of the renewable energy that gets more attention from many countries [1]. According to law number 30, the year 2007 article 29 paragraph 2 about the energy, the development of energy directed to the development of renewable energy [2]. According to data from IRENA [3] (The International Renewable Energy Agency) at 2015 the distribution of solar photovoltaic installations in Indonesia is only $0.1 \%$ of the total

* Corresponding author: imamabadi02@gmail.com 
installed renewable energy technology, the world alone is installed at $11.2 \%$ of the overall renewable energy technology installed, while Indonesia is a country that is on the equator which is always sunlit throughout the year. In addition, the range of the year 2010 to 2015 decreased the price of solar PV modules by $75 \%$ to $80 \%$.

Solar PV needs the right position to get maximum energy yield [4, 5]. The solar tracker can implement with one-axis solar tracking if desired higher accuracy can use two-axis solar tracking. Two-axis solar tracking has two kinds that are solar tracking and azimuth tracking [6]. Solar tracker not always needs to point right to the sun; when it missed $10 \%$, the resulting output is still $98.5 \%$ of that produced by solar tracker that is always pointing towards the sun. Cloudy areas, the gain is about $20 \%$ annually, while in bright areas, it can reach $30 \%$ to $40 \%$ annually [7]. ANFIS stands for an adaptive neuro-fuzzy interface system. ANFIS is a method with a combination between the neural network and the fuzzy system. Some data will be trained firstly then implied to the fuzzy system [8].

In previous studies, the solar tracking system is used in a tropical area. The study conducted in 2015 showed that a single axis solar tracking system, when used in the tropical area, resulted in a more extensive power conversion of about $25 \%$ compared to fixed panels [9]. Research in 2012 in Malaysia, the performance ratio of P-Si type photovoltaics of $59.40 \%$, uses a solar tracker system with one axis [10]. Therefore, it is necessary to compare the performance between two methods of tracking the sun that is with one axis and two-axis using ANFIS (Adaptive Neuro-Fuzzy Inference System) control in the tropical area, so it can show the difference in performance produced by the solar tracker system with one axis and two-axis solar tracking.

The research will be done by simulating one axis and two-axis solar tracking system with ANFIS (Adaptive Neuro-Fuzzy Inference) control with active sun-tracking mode. The single-axis solar tracking system uses two LDR, each on the east and west. Two-axis solar tracking system uses four LDR, each on the north, south, east, and west. Use $170 \mathrm{~mm} \times 250 \mathrm{~mm}$ paper size $(\mathrm{W} \times \mathrm{H} \mathrm{mm})$ and adjust the margins to those shown in the Table 1. The final printed area will be $130 \mathrm{~mm} \times 210 \mathrm{~mm}$.

Table 1. Parameters of DC motor.

\begin{tabular}{|c|c|}
\hline Motor Parameters & Parameter Value Motor \\
\hline $\mathrm{Ke}$ & $12.84369 \mathrm{~V} \mathrm{~s} \mathrm{rad}^{-1}$ \\
\hline $\mathrm{Kt}$ & $12.84437 \mathrm{Nm} \mathrm{A}^{-1}$ \\
\hline $\mathrm{R}$ & $22.4245 \Omega$ \\
\hline $\mathrm{L}$ & $0.006386 \mathrm{Henry}^{-}$ \\
\hline $\mathrm{Jm}$ & $0.723779 \mathrm{Nm} \mathrm{s}^{2}$ \\
\hline $\mathrm{Bm}$ & $3.434949 \mathrm{Nm} \mathrm{s} \mathrm{rad}^{-1}$ \\
\hline
\end{tabular}

\section{Literature review}

\subsection{Solar tracking system}

The solar tracking system is a system that acts to detect the sun's position by means of a light sensor and controls the photovoltaic so that it is always perpendicular to the sun by changing the pitch and yaw axis of a solar tracker. The purpose of the solar tracking system is to keep photovoltaic always perpendicular to the sun, and it can optimize the output power of photovoltaic. The output power of the photovoltaic will produce greater energy 
than the photovoltaic that is not always perpendicular to the sun. Sunlight comprises several sensor components, controller, DC motor, battery, and photovoltaic [11].

\subsection{Light sensor (LDR)}

LDR (Light Dependent Resistor) is one of the light sensors whose resistance changes depending on the intensity of incoming light. LDR is used to convert light energy into electrical energy. An LDR is strung together with one resistor whose value can be changed and one resistor whose value is fixed. This series circuit has functioned as a voltage divider. The voltage divider in Equation (1):

$$
V_{\text {out }}=\frac{R 2}{R 1+r 2} V_{\text {in }}
$$

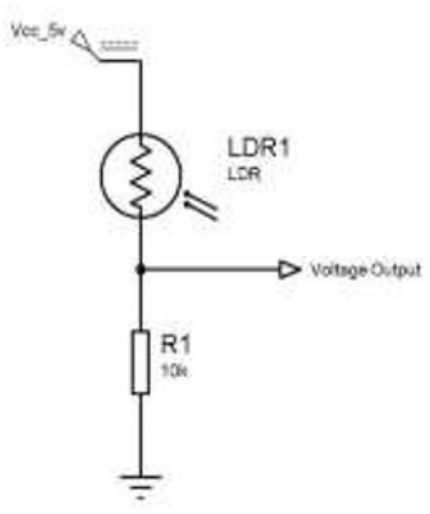

Fig. 1. Voltage devider and LDR.

\subsection{ANFIS architecture}

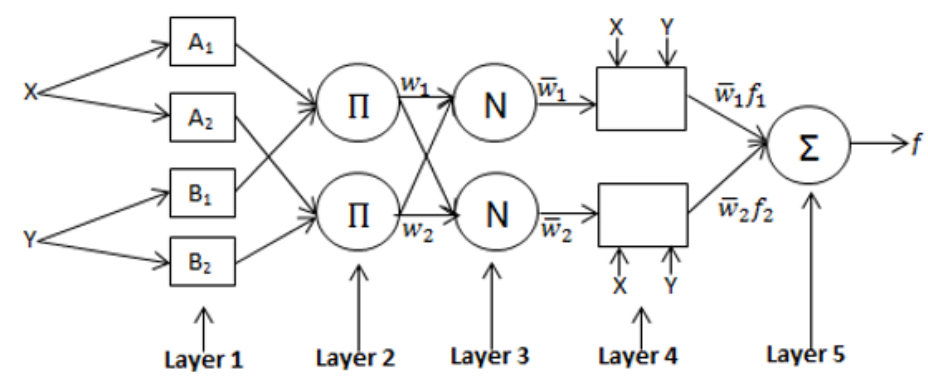

Fig. 2. Voltage Divider and LDR.

ANFIS stands for Adaptive Neuro-Fuzzy Inference System. ANFIS is also an amalgamation of an artificial neural network method with a fuzzy system. Adaptive networks are usually used in a variety of modeling, decision-making, controlling, and signal processing applications. The adaptive network class is functionally equivalent to a fuzzy system. The architecture of this is called ANFIS. The set parameters are set to apply hybrid 
learning rules for ANFIS architecture that represent both Sugeno and Tsukamoto fuzzy models. The layers in the ANFIS architecture [8, 12] shown in Figure 2.

The first layer has adaptive nodes whose parameter values may change with learning. The node function as follows in Equation (2):

$$
O_{i}^{1}=\mu_{A i}(x)
$$

Where $\mathrm{x}$ is the input for node $i$ and $\mathrm{Ai}$ is the language naming associated with the node function for the Gaussian function (commonly used), which is specified in Equation (3):

$$
\mu_{A i}(x)=\exp \left[-0.5\left(\frac{x-c_{i}}{\sigma_{i}}\right)^{2}\right]
$$

Where $\left\{\sigma_{i}, c_{i}\right\}$ is set parameter. The parameters in this layer are shown as the premise parameter. The second layer has a non-adaptive node whose parameter values are fixed. The function of this node is as a multiplication of each input signal. The function of the node is as in Equation (4):

$$
O_{i}^{2}=w_{i}=\mu_{A i}(x) \times \mu_{B i}(x), \quad i=1.2
$$

Each output node of this layer represents the degree of activation for each rule.

This third layer is a non-adaptive node that can display the function of the normalized firing strength that is the output ratio of the i-th nodes in the previous layer to the entire output of the previous layer. The function of the node is as in Equation (5):

$$
O_{i}^{3}=\bar{w}=\frac{w_{i}}{w_{1}+w_{2}}, \quad i=1.2
$$

The output of this layer is called normalized firing strength.

In the fourth layer, all the nodes are adaptive to the normalized activation degree of layer 3. The function of the node is as in Equation (6):

$$
O_{i}^{4}=\bar{w}_{i} f_{i}=\bar{w}_{i}\left(a_{i}^{1} x+a_{i}^{2} y+a_{i}^{0}\right)
$$

This fifth layer contains only one non-adaptive node with a function to sum all inputs. The function of the node is as in Equation (7):

\section{Research methodology}

$$
O_{i}^{5}=\sum_{i} \bar{w}_{i} f_{i}=\frac{\sum_{i} w_{i} f_{i}}{\sum_{i} w_{i}}
$$

\subsection{System modelling}

Modeling of one-axis and two-axis solar tracking system is done by using MATLAB/Simulink to perform simulation, using component parameters to obtain the simulation of one-axis and two-axis solar tracking system. The LDR sensor is a sensor that converts light energy into electricity. It is obtained from changes in the resistance found in the LDR sensor when exposed to sunlight. In the modeled photovoltaic, the output voltage of the fixed resistor is $1000 \Omega$. The relationship equation between irradiance and resistance to LDR sensor can be explained as in Equation (8):

Where:

$$
\log R=-\frac{3}{4} \log I+5
$$

[12]. = Resistance of LDR sensors $\operatorname{LDR}(\Omega)$

I = Irradiance into the LDR sensor $\left(\mathrm{W} / \mathrm{m}^{2}\right)$ 


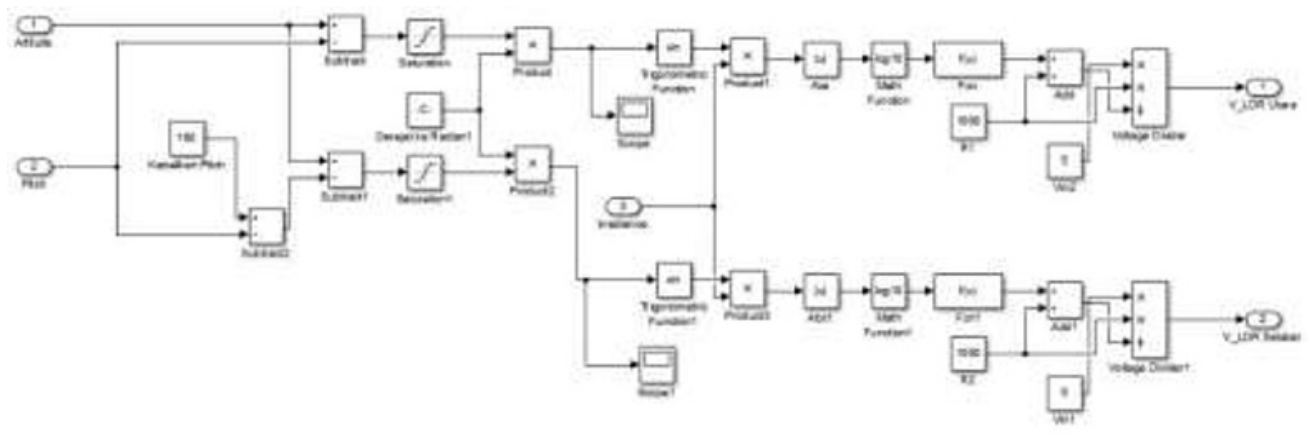

Fig. 3. LDR sensor modeling.

\subsubsection{Modeling of DC motor}

The DC motor is the driving force of the PV panel to keep up with the sun. One-axis solar tracking system uses one motor with pitch angle tracking, while the two-axis sun tracking system uses two motors with tracking pitch and yaw angles. The pitch angle moves between the angles of $0^{\circ}$ and $180^{\circ}$ and the yaw angle moves between angles $0^{\circ}$ and $360^{\circ}$ at low speeds.

DC motors can also be used to drive PV panels in a solar tracking system. The advantages of this DC motor rotation speed can be set so that PV panels can follow the sun precisely. The modeling of a DC motor, which converts the voltage value to rpm speeds is as in Equation (9) and Equation (10), follows [13]:

$$
\begin{gathered}
V_{a}(t)=R_{a} \cdot I_{a}(t)+L_{a} \cdot \frac{d I_{a}(t)}{d t}+K_{b} \cdot \omega(t) \\
K_{t} \cdot I_{a}(t)=J_{m} \frac{d \omega(t)}{d t}+B_{m} \cdot \omega(t)
\end{gathered}
$$

Then, the equations of voltage and current in DC motors are transformed in Laplace transformation:

$$
\begin{gathered}
V_{a}(s)=R_{a} \cdot I_{a}(s)+L_{a} \cdot I_{a}(s) s+K_{b} \cdot \omega(s) \\
K_{t} \cdot I_{a}(s)=J_{m} \cdot \omega(s) s+B_{m} \cdot \omega(s)
\end{gathered}
$$

After that, the substitution result is:

$$
V_{a}(s)=\omega(s) \cdot \frac{1}{K_{t}} \cdot\left[L_{a} \cdot J_{m} \cdot s^{2}+\left(R_{a} \cdot J_{m}+L_{a} \cdot B_{m}\right) s+\left(R_{a} \cdot B_{m}+K_{b} \cdot K_{t}\right)\right]
$$

With the relationship value between angle and speed is $\theta(s)=\frac{1}{s} \omega(s)$, the relationship between voltage and angle is as in Equation (14) follows:

$$
\frac{\theta(s)}{V_{a}(s)}=\frac{K_{t}}{\left[L_{a} \cdot J_{m} \cdot s^{3}+\left(R_{a} \cdot J_{m}+L_{a} \cdot B_{m}\right) s^{2}+\left(R_{a} \cdot B_{m}+K_{b} \cdot K_{t}\right) s\right]}
$$

Where:

$\mathrm{Va}=$ Armature Voltage $(\mathrm{V})$

$\mathrm{Ra}=$ Armature Resistance $(\mathrm{R})$ 
$\mathrm{La}=$ Armature Inductance $(\mathrm{H})$

Ia = Armature Current (A)

$\omega=$ Angular Speed $\left(\mathrm{rad} \mathrm{s}^{-1}\right)$

$\theta=$ Position of Angular Shaft Rotor

(rad) $\mathrm{Jm}=$ Motor Inertia $\left(\mathrm{Nm} \mathrm{s}^{2}\right)$

$\mathrm{Bm}=$ Viscous Friction Coefficient $\left(\mathrm{Nm} \mathrm{s} \mathrm{rad}^{-1}\right)$

$\mathrm{Kt}=$ Torque Constant $\left(\mathrm{Nm} \mathrm{A}^{-1}\right)$

$\mathrm{Kb}=$ Back EMF Constant $\left(\mathrm{V} \mathrm{s} \mathrm{rad}{ }^{-1}\right)$

The parameters of DC motor are obtained with the following Equation (15 to 17) [14];

$$
\begin{gathered}
K_{e}=\frac{\text { Voltage }[V]}{\text { Velocity }\left[\frac{r a d}{s}\right]} \\
K_{t}=\frac{K_{e}}{0.11827}\left[\frac{N_{m}}{A}\right] \\
J_{m} \frac{d \omega(t)}{d t}+B \omega(t)=\operatorname{Tm}(t)
\end{gathered}
$$

This DC motor has connected gearbox with ratio1:348.079 2. After the DC motor data were taken and the calculation of DC motor parameters according to equations, we obtain the following parameter values:

\subsubsection{Photovoltaic modeling}

Photovoltaic modeling is done by using photovoltaic parameters and current and voltage output equations on photovoltaic, as for the following Equation (18) and Equation (19) [14]:

$$
\begin{gathered}
I=\left[\left(\frac{s}{s_{r e f}}\right)\left(\mu\left(T-T_{r e f}\right)+1\right)-I_{s c}\right]+I_{n} \\
V=V_{n}-\Phi\left(\mathrm{T}-T_{r e f}\right)-R_{p v}\left(I-I_{n}\right)
\end{gathered}
$$

Table 2 Parameter of photovoltaic.

\begin{tabular}{|c|c|c|}
\hline No & Parameter & Parameter Value \\
\hline 1 & Short Circuit Current, Isc & $1.25 \mathrm{~A}$ \\
\hline 2 & Open Circuit Current, Voc & $21.5 \mathrm{~V}$ \\
\hline 3 & Temperature Coefficient of Isc, $\mu$ & $0.00005 \mathrm{~A}^{\circ} \mathrm{C}^{-1}$ \\
\hline 4 & Temperature Coefficient of Voc, $\phi$ & $-0.0036 \mathrm{~V}^{\circ} \mathrm{C}^{-1}$ \\
\hline 5 & Refrence Voltage, Vn & $17.2 \mathrm{~A}$ \\
\hline 6 & Reference Current, In & $1.16 \mathrm{~A}$ \\
\hline 7 & Maximum Power at STC & $20 \mathrm{~W}$ \\
\hline 8 & PV Internal Resistance, Rpv & $1.11 \Omega$ \\
\hline
\end{tabular}




\subsection{Design of ANFIS control}

ANFIS is a combination of neural networks and fuzzy logic. Artificial neural networks that will determine the membership function and rule base of fuzzy logic. ANFIS requires a pair of train data to be trained on artificial neural networks. The input of this training data is error and delta error while the output of this training data is PWM. The ANFIS control uses the membership function with the type of Gauss and the membership number of five represents Clockwise Fast (CWF), Clockwise Slow (CWS), Stop (S), Counter Clockwise Slow (CCWS) and Counter Clockwise Fast (CCWF). The Membership Function of the input before being trained is as shown in Figure 4. The membership function of the input after being trained from each ANFIS control for DC motor control on the pitch and yaw axis as shown in Figure 5 and Figure 6.

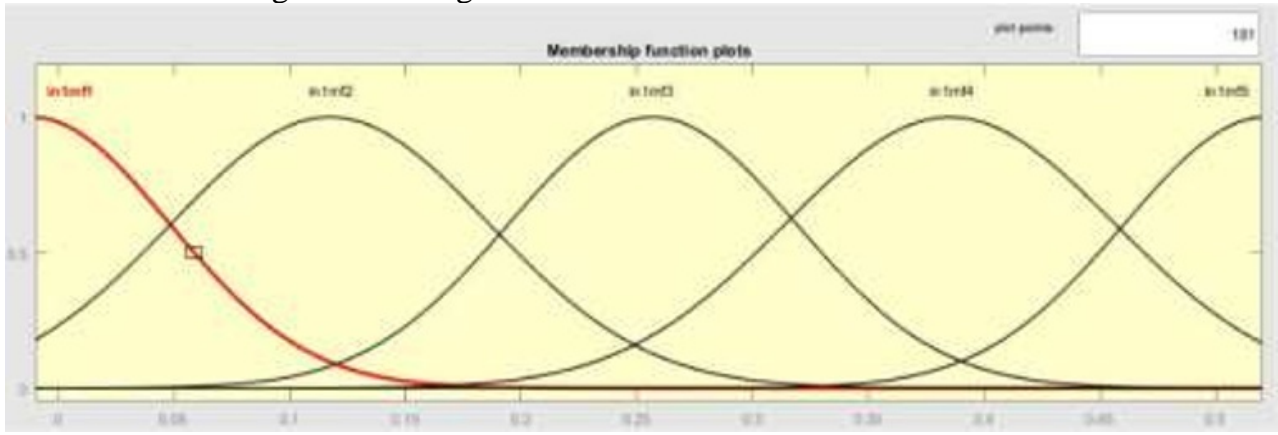

Fig. 4. Membership function of error and delta error on pitch and yaw axis.

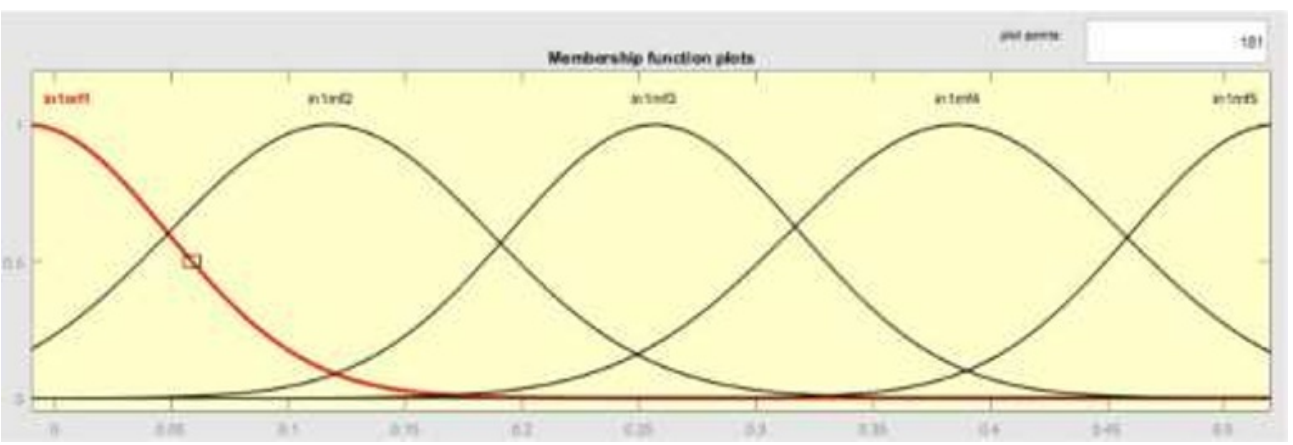

(a)

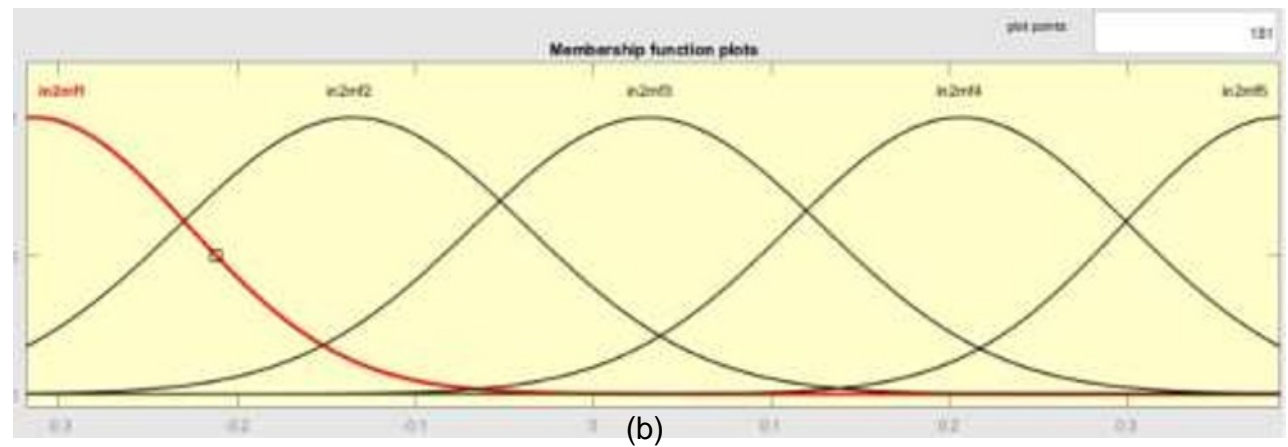

Fig. 5. Membership function of (a) Error and (b) Delta error on pitch axis. 


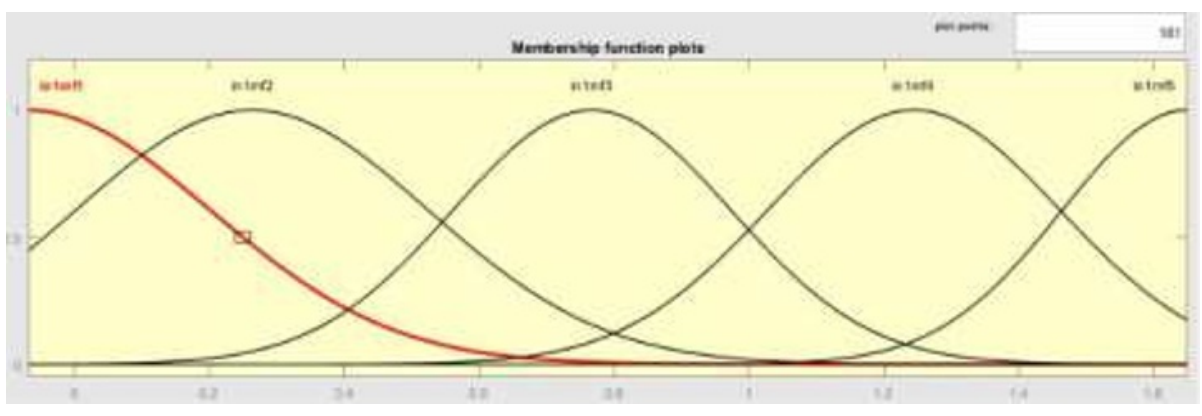

(a)



(b)

Fig. 6. Membership function of (a) Error and (b) Delta error on yaw axis.

\section{Result and discussion}

In the test setpoint, use three setpoint angles of sun elevation and three setpoint angle azimuth suns. For altitude angles the sun uses setpoint angle $30^{\circ}, 60^{\circ}$, and $90^{\circ}$ while for the azimuth angle of the sun use setpoint angle $30^{\circ}, 60^{\circ}$, and $90^{\circ}$. The performance index of the pitch angle response is as shown in Table 3.

Table 3. Performance index of pitch angle.

\begin{tabular}{|c|c|c|c|c|}
\hline \multirow{2}{*}{ No } & \multirow{2}{*}{ Performance Index } & \multicolumn{3}{|c|}{ Angle Value } \\
\cline { 3 - 5 } & & $\mathbf{3 0}^{\circ}$ & $\mathbf{6 0}^{\circ}$ & $\mathbf{9 0}^{\circ}$ \\
\hline 1 & Rise Time & $3.128 \mathrm{~s}$ & $6.286 \mathrm{~s}$ & $9.444 \mathrm{~s}$ \\
\hline 2 & Error Steady State & -0.00735 & -0.00735 & -0.00735 \\
\hline 3 & $\%$ Maximum Overshoot & $2.577 \%$ & $1.531 \%$ & $0.008889 \%$ \\
\hline 4 & Settling time & $4.523 \mathrm{~s}$ & $7.681 \mathrm{~s}$ & $10.838 \mathrm{~s}$ \\
\hline
\end{tabular}

The performance index of the yaw angle response is as shown in Table 4.

Table 4. Performance index of yaw angle.

\begin{tabular}{|c|c|c|c|}
\hline \multirow{2}{*}{ Time } & \multicolumn{3}{|c|}{ Efficiency ( \%) } \\
\cline { 2 - 4 } 1 d & 1 Axis to fixe d & 2 Axis to fixe d & 2 Axis to 1 Axis \\
\hline 3 d & $23.09 \%$ & $50.16 \%$ & $21.99 \%$ \\
\hline 5 d & $13.63 \%$ & $36.67 \%$ & $20.28 \%$ \\
\hline 7 d & $16.11 \%$ & $46.04 \%$ & $25.78 \%$ \\
\hline
\end{tabular}


Tracking test on the sun tracking system serves to determine the response of the system when the setpoint changed. The test is done by changing the setpoint from $30^{\circ}$ raised to $60^{\circ}$ then lowered to $40^{\circ}$ then raised again to $70^{\circ}$. One of the important goals of the solar system applied to photovoltaics is to increase the output power. In the performance test on photovoltaic compared to output power output between PV that does not use the system of tracking the sun (fixed), solar tracking system with one axis and solar tracking system with two axes with data taking with a span of $1 \mathrm{~d}, 3 \mathrm{~d}, 5 \mathrm{~d}$ and $7 \mathrm{~d}$.

The PV power output profile is as shown in Figures 7. The efficiency of PV on one axis, two axis, and fixed axis systems is as shown in Table 5.

Table 5. Photovoltaic efficiency.

\begin{tabular}{|c|c|c|c|c|}
\hline \multirow{2}{*}{ No } & \multirow{2}{*}{ Performance Index } & \multicolumn{3}{|c|}{ Angle Value } \\
\cline { 3 - 5 } & & $\mathbf{3 0}^{\circ}$ & $\mathbf{6 0}^{\circ}$ & $\mathbf{9 0}^{\circ}$ \\
\hline 1 & Rise Time & $3.203 \mathrm{~s}$ & $6.235 \mathrm{~s}$ & $9.267 \mathrm{~s}$ \\
\hline 2 & Error Steady State & -0.00806 & -0.00806 & -0.00806 \\
\hline 3 & $\%$ Maximum Overshoot & $1.531 \%$ & $0.505 \%$ & $0.004778 \%$ \\
\hline 4 & Settling time & $3.836 \mathrm{~s}$ & $6.867 \mathrm{~s}$ & $9.899 \mathrm{~s}$ \\
\hline
\end{tabular}

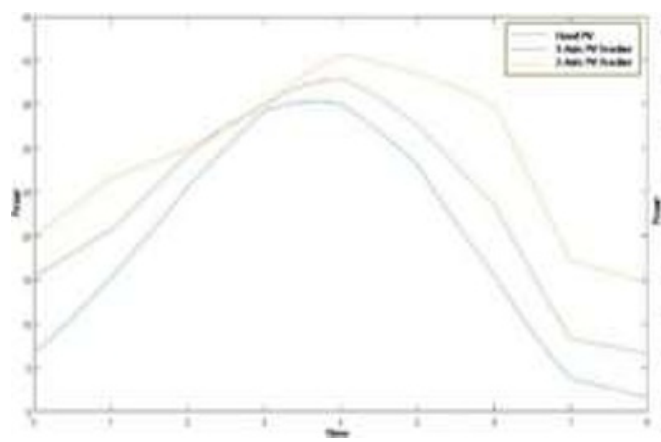

(a)

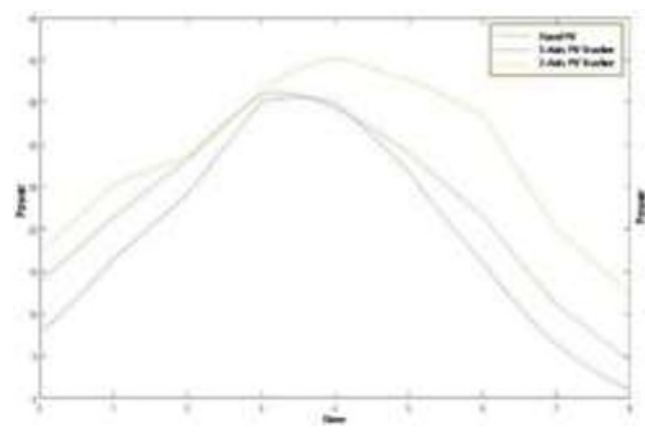

(c)

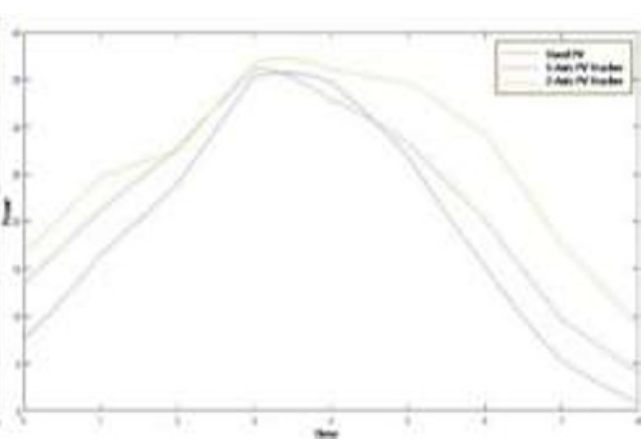

(b)

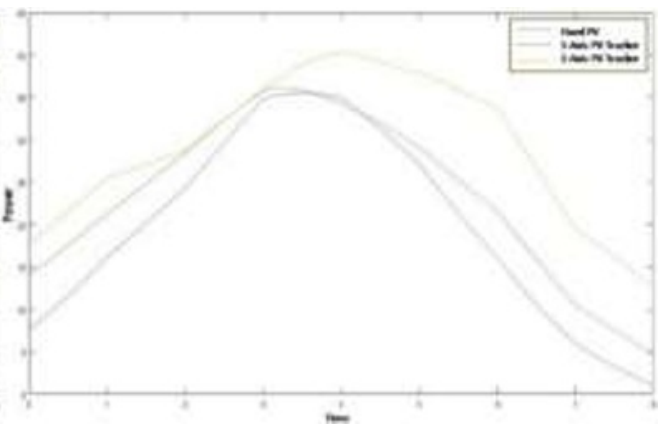

(d)

Fig.7. PV Power output profile for (a) $1 \mathrm{~d}$ (b) $3 \mathrm{~d}$ (c) $5 \mathrm{~d}$ and (d) $7 \mathrm{~d}$. 


\section{Conclusion}

Based on the research that has been done, ANFIS control with point pitch test resulted in rising time performance index of $3.128 \mathrm{~s}, 6.28 \mathrm{~s}$, and $9.44 \mathrm{~s}$, maximum overshoot $2.577 \%$, $1.533 \%$, and $0.0089 \%$, settling time of $4.523 \mathrm{~s}, 7.681 \mathrm{~s}$ and $10.838 \mathrm{~s}$ at each corner $30^{\circ}$, $60^{\circ}$, and $90^{\circ}$ and error steady state $-0.0735 \mathrm{~V}$. ANFIS control with setpoint yaw test yielded rise time index of $3.203 \mathrm{~s}, 6.235 \mathrm{~s}$, and $9.267 \mathrm{~s}$, maximum \% overshoot $1.531 \%$, $0.505 \%$, and $0.0048 \%$, settling time $3.836 \mathrm{~s}, 6.867 \mathrm{~s}$ and $9.899 \mathrm{~s}$ at each corner $30^{\circ}, 60^{\circ}$, and $90^{\circ}$ and error steady state $-0.0081 \mathrm{~V}$. The two-axis solar tracking system has a greater power output than the single axis solar tracking and fixed photovoltaic. The efficiency of power (data for $7 \mathrm{~d}$ ) from a one-axis solar tracking system to the solar tracking system with fixed PV is $15.98 \%$, while for the efficiency of the two-axis sun measuring system against the solar tracking system with fixed PV is $46.65 \%$, while the efficiency of the tracking system two axes of sun to one axis sun track system is $26.442 \%$. In the next research, data used to train ANFIS should represent positive values and negative values so that ANFIS dicks can respond well when setpoints are raised or lowered.

\section{References}

1. E. Díaz-Dorado, A. Suárez-García, C.J. Carrillo, J. Cidrás, Renew. Energy. 36,6:1826-1835(2011). https://www.sciencedirect.com/science/article/pii/S0960148110005562

2. President of the Republic of Indonesia. Undang-Undang Republik Indonesia Nomor 30 Tahun 2007 Tentang Energi. [Republic of Indonesia Law Number 30 Year 2007 Concerning Energy] Jakarta: Republic of Indonesia. (2007) [in Bahasa Indonesia]. https://jdih.esdm.go.id/peraturan/uu-30-2007.pdf

3. The International Renewable Energy Agency. Decentralised RE Data Review, Indonesia [Online] from http://resourceirena.irena.org/gateway/dashboard/ (2016). [Accessed on June 2, 2020].

4. Batayneh, Wafa, A. Owais, M. Nairoukh, Automat. Constr, 29:100-106(2013). https://www.sciencedirect.com/science/article/pii/S0926580512001550

5. I. Sefa, M. Demirtas, I. Çolak., Energ. Convers. Manage. 50,11:2709-2718(2009). https://www.sciencedirect.com/science/article/pii/S0196890409002349

6. X. Li, Z. Deng, Z. Chen, Q. Fei. IEEE Transactions on Industrial Electronics, 58,2:450-464(2011). https://ieeexplore.ieee.org/document/5439835?reload=true

7. M. Hossein, K. Alizera, J. Arzhang, M. Hossein, A. Karen, S. Ahmad. Renew. Sust. Energ. $\quad$ Rev. 13,8:1800-1818(2009). https://ideas.repec.org/a/eee/rensus/v13y2009i8p1800-1818.html

8. I. Abadi, C. Imron, R.D. Noriyati. E3S Web Conf. 43,01014:1-8(2018). https://www.e3sconferences.org/articles/e3sconf/abs/2018/18/e3sconf_astechnova2017_01014/e3scon f_astechnova2017 01014.html

9. J.S.R. Jang, C.T. Sun, E. Mizutani, Neuro-Fuzzy and soft computing: A computational approach to learning and machine intelligence. New Jersey: Pearson (1997). p. 648. https://www.amazon.com/Neuro-Fuzzy-Soft-Computing-ComputationalIntelligence/dp/0132610663 
10. Y. Garcia, O. Diaz, C. Agudelo, WIT Trans. Ecol. Environ. 195:197-207(2015). https://www.researchgate.net/publication/300634197_Performance of a solar_PV tr acking system on tropic regions

11. M.A. Ghazali, A.M.A. Rahman, Energy Environ. Res., 2,1:235-243(2012). https://www.researchgate.net/publication/284708513 The Performance of Three Di fferent_Solar_Panels for_Solar_Electricity_Applying_Solar_Tracking_Device under the_Malaysian_Climate_Condition

12. A. Mohanad, M.A. Al-Nimr, Y. Qaroush, Energy Convers. Manag. 26,7-8:12291245(2005). https://www.sciencedirect.com/science/article/pii/S0196890404001529

13. J. Maknunah, I. Abadi, I. Abdurrahman, C. Imron, AIP Conference Proceedings, 2088,1:030018(2019). https://aip.scitation.org/doi/10.1063/1.5095323

14. M. Namazov, O. Basturk, Turkish Journal of Fuzzy Systems, 1,1:36-54(2010). https://pdfs.semanticscholar.org/0636/03c8159975402271384295a4b60b3a5f21b9.pdf 